\title{
Pre-consultation information about one's physician can affect trust and treatment outcome expectations
}

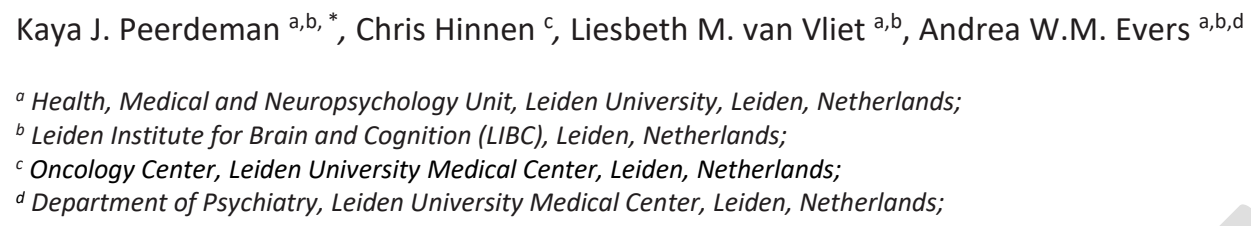

Note: The current version of the article is a preprint and has not yet been subject to peer review.

\section{Abstract}

Objective: Information about physicians' skills is increasingly available on the internet and consulted by patients. The impact of such information on patient expectations is largely unknown. The aim of the present study was to investigate whether pre-consultation information about the competence and empathic skills of a physician may impact pre-consultation trust and treatment outcome expectations in mild and severe medical conditions.

Methods: In this experimental web-based study, participants $(n=237)$ read vignettes describing competence and empathic skills (low versus high) of a fictive physician who would surgically remove a mole or melanoma (low versus high severity). Participants next rated trust in the physician and treatment outcome expectations.

Results: High physician's competence and empathy raised pre-consultation trust in the physician, regardless of condition severity. Both high competence and empathy also increased expected surgery success, while only high competence reduced expected side effects.

Conclusion: Pre-consultation information highlighting a physician's competence and/or empathy may lead to higher trust in that physician, higher expected surgery success, and lower expected side effects. Practice Implications: Physicians and hospital staff should be aware of the effects of online information available and might, for example, provide profiles on hospital websites emphasizing competence and empathy of healthcare providers.

Keywords: competence, empathy, trust, expectations, patient-physician relationship, cancer, vignette study 


\section{Introduction}

Information about physicians' skills is increasingly available on the internet and consulted by patients [1]. This information may contain objective information (e.g., about physicians' competencies), provided by, for example, a hospital website [2], or it may consist of patients experiences (e.g., of empathic skills) placed on social media or public physician rating websites [3]. While previous research found that such online information may influence patients' choice of physician [1,4], it is largely unknown how such information may affect patients' trust in physicians and treatment outcome expectancies, which are important predictors of treatment outcomes.

Particularly the communication of physicians' competence and empathic skills may impact whether patients experience their physician as trustworthy $[5,6]$. Trust in one's physician is highly important for patient wellbeing, and likely especially when patients are confronted with a potentially life-threatening illness such as cancer, when a sense of vulnerability is high [7-9]. A trusting patient-physician relationship has been associated with confidence in and adherence to treatment regimens [10], as well as treatment outcomes like physical functioning [11]. Patients' views of physician's competence and empathic skills might also shape and interact with expected treatment outcomes [12] and these expectations have been associated with treatment adherence $[3,14]$ and affect treatment outcomes such as pain relief $[15,16]$. Individual differences in the effects of communication of competence and empathy might partially depend on patients' attachment style [5] or general tendency to trust others [9].

The present web-based experimental vignette study focused on whether pre-consultation information about the competence and empathic skills of a physician may impact patients' pre-consultation trust in the physician. Secondary, we assessed if this influence might be stronger in case of severe conditions (removal melanoma), as compared to mild conditions (cosmetic removal mole). Furthermore, we assessed effects of competence and empathic skills on expected surgery success and side effects. Additionally, we explored if individual differences in attachment style and general trust moderate effects of competence and empathy on trust in the physician.

\section{Methods}

\subsection{Design \& Vignette}

We used a $2 \times 2 \times 2$ between-subjects vignette design. We created a written vignette containing fictive information about an upcoming surgical removal of a mole in which we varied information about 1) the severity of the condition (low: low-risk surgical removal of benign mole versus high: high-risk surgical removal of melanoma), 2) the physician's competence (low versus high), and 3) the physician's empathy (low versus high). The vignette was developed by experienced (clinical) psychologists based on communication and placebo effect research $[17,18]$. It was pilot tested among physicians (including dermatologists), researchers, and lay people to ensure realism and manipulation success. See the Appendix for the vignette.

\subsection{Participants}

The survey was completed by 237 participants, who were predominantly university students (mean age $21.7 \pm 7.5$, range $18-64,94 \% \leq 26$ years; $89 \%$ female, all fluent in Dutch). A minority indicated a personal or familial history of cosmetic (15.6\% versus $35.9 \%$ ) or medical (1.3\% versus $29.1 \%)$ mole removal, with generally positive experiences ( $7.3 \pm 1.6$ on $0-10$ scale). No exclusion criteria applied. The study was approved by the institute's ethics committee (CEP18-1019/394). 


\subsection{Procedure}

Participants were recruited via advertisements (at university and social media). Potential participants were informed about the general study aims and participation procedures. Participants who provided informed consent, acted as analogue patients [19] and were asked to read and vividly imagine the fictive situation described in one of the 8 vignette variants (to which they were automatically randomized) and to fill out questionnaires, all via a secured online system (Qualtrics). Participants were reimbursed with course credits or a chance to win a gift voucher. Median study completion time was 7 minutes.

\subsection{Questionnaires}

Manipulation checks. Manipulations were checked via participants' judgements of condition severity, physician's competence, and physician's empathy on 0-10 numerical rating scales.

Outcome measures. Trust in the physician was assessed with the Wake Forest Physician Trust Scale [20], adjusted to apply to the vignette (Cronbach's alpha=.86). Expected surgery success and side effects were measured with 0-10 numerical rating scales.

Participant characteristics. Attachment style was assessed with the Anxiety and Avoidance sales of the modified and shortened Experiences in Close Relationship scale (ECR-M16) [21] (Cronbach's alpha=.83 and .82, respectively). Trust in general was assessed with the General Trust Scale [22], translated to Dutch via a forward and backward procedure (Cronbach's alpha=.71). Demographical data on age, sex, student status, fluency in Dutch, as well as history of mole removal were collected.

\subsection{Statistical analyses}

All analyses were run in IBM SPSS Statistics version 26 with $\alpha=.05$. Manipulation checks were run using three one-way ANOVAs, with severity, competence, and empathy as independent variables (IVs; each with two levels: low versus high) and associated severity, competence, and empathy ratings as dependent variables. Effects on trust in the physician were tested with 2x2 ANOVAs; one with competence and severity as IVs, and one with empathy and severity as IVs. Effects on expected treatment outcomes were tested with one-way ANOVAs, with either competence or empathy as IV (interactions with severity were not analyzed because expected surgery success and risks were manipulated in the vignette). We explored if attachment style and general trust moderated the effects of competence and empathy on trust in the physician with PROCESS 3.4 [23]. Data and SPSS syntax will be available via DANSeasy.

\section{Results}

\subsection{Manipulation checks}

Manipulations were successful for severity of the condition $\left(F(1,235)=662.1, p<.001, \eta_{p}{ }^{2}=.74\right)$, physician's competence $\left(F(1,235)=125.6, p<.001, \eta_{p}{ }^{2}=.35\right)$, and physician's empathy $(F(1,235)=684.7, p<.001$, $\left.\eta_{\mathrm{p}}^{2}=.74\right)$. See Table 1.

Table 1. Manipulation checks.

\begin{tabular}{r|llll} 
& Low & \multicolumn{3}{l}{ High } \\
\hline & Mean & SD & Mean & SD \\
\hline Severity & 1.9 & 2.1 & 7.9 & 1.5 \\
Competence & 5.8 & 2.0 & 8.4 & 1.5 \\
Empathy & 3.1 & 2.0 & 8.6 & 1.1
\end{tabular}




\subsection{Trust in the physician}

Both physician's high competence and empathy raised pre-consultation trust in the physician as compared to low competence and empathy (competence: $F(1,233)=53.2, p<.001, \eta_{p}{ }^{2}=.19$; empathy: $\left.F(1,233)=38.3, p<.001, \eta_{p}{ }^{2}=.14\right)$. These effects were independent of severity (interaction competence * severity: $F(1,233)=0.0, p=.905, \eta_{p}^{2}=.00$; interaction empathy * severity: $\left.F(1,233)=2.1, p=.146, \eta_{p}^{2}=.01\right)$. See Figure 1 and Table 2.

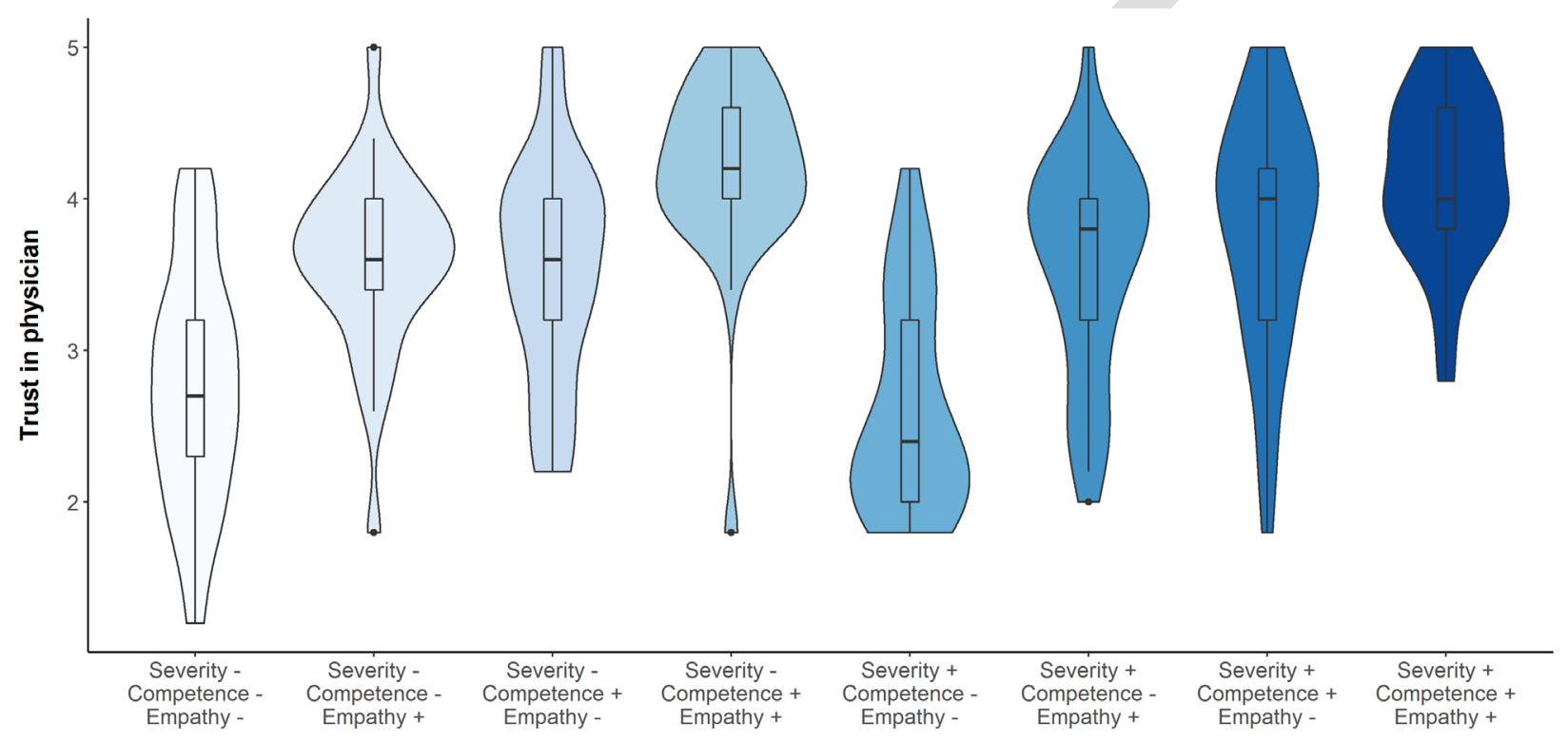

Vignette version

Figure 1. Violin plot showing data distribution with box plot of trust in the physician per vignette version (created with $\mathrm{R}$ package ggplot2). 
Table 2. Influence of pre-consultation information on trust in the physician and expected treatment outcomes.

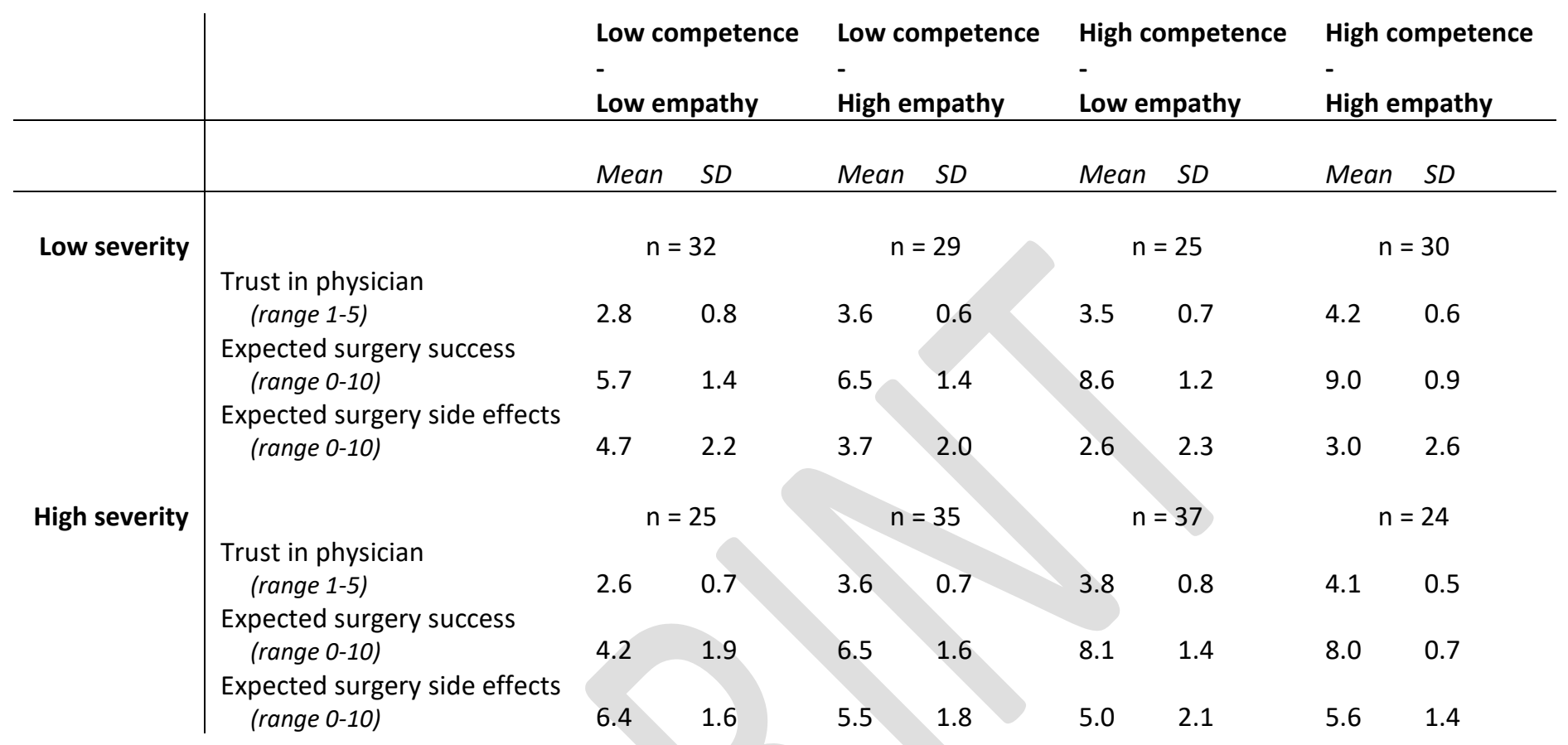

\subsection{Expected treatment outcomes}

High competence and high empathy raised expected surgery success as compared to their low variants (competence: $F(1,235)=170.0, p<.001, \eta_{p}{ }^{2}=.42$; empathy: $\left.F(1,235)=7.9, p=.005, \eta_{p}{ }^{2}=.03\right)$. Only high competence increased expected surgery side effects (competence: $F(1,235)=10.7, p=.001, \eta_{p}{ }^{2}=.04$; empathy: $\left.F(1,235)=0.8, p=.372, \eta_{p}{ }^{2}=.00\right)$. See Table 2 .

\subsection{Moderation by attachment style and general trust}

The effect of competence on trust in the physician was not significantly moderated by anxious attachment style $(\beta=-.10, \mathrm{SE}=.13, \mathrm{t}=-0.75, \mathrm{p}=.456)$. Lower avoidant attachment $(\beta=-.34, \mathrm{SE}=.14, \mathrm{t}=-2.47$, $p=.014)$ and higher general trust $(\beta=.44, S E=.20, t=2.26, p=.025)$ predicted a slightly greater effect of competence on trust. The effect of empathy on trust in the physician was not significantly moderated by anxious or avoidant attachment style $(\beta=-.14, \mathrm{SE}=.13, \mathrm{t}=-1.08, \mathrm{p}=.283 ; \beta=-.17, \mathrm{SE}=.14, \mathrm{t}=-1.21, \mathrm{p}=.228$, respectively) or general trust $(\beta=.16, \mathrm{SE}=.20, \mathrm{t}=0.78, \mathrm{p}=.435)$.

\section{Discussion and Conclusion}

\subsection{Discussion}

The current web-based experiment showed that written pre-consultation information highlighting a physician's competence and empathy lead to higher pre-consultation trust in the physician, regardless of severity of the medical condition. These descriptions also led to higher expectations of surgery success, while only high competence lead to lower expectations of surgery side effects. The effects of competence and empathy on trust were largely independent of people's attachment style and general trust. 
The present results are the first to indicate that written pre-consultation information about physicians' skills, which is increasingly available and consulted online, does not only affect patients' selection of a physician [1,4], but also patients' pre-consultation trust and treatment outcome expectancies. Trust and outcome expectancies in turn are known to impact the patient-physician relationship $[5,6]$ and treatment adherence and outcomes [10,11,13-16] and are considered core mechanisms of placebo effects [24]. Notably, the observed effect sizes preliminary indicate that views of physicians' competence affect expected treatment outcomes more strongly than views of empathic skills, although these differences were not observed in previous research where competence and empathy were manipulated in the lab [12]. Meanwhile, competence and empathic skills contributed comparably to trust in the physician. Importantly, the use of a vignette allowed us to directly compare a mild versus severe condition, suggesting that the effects of communicating competence and empathic skills on trust in the physician are no greater for severe medical conditions, despite previous notions that increased vulnerability when at greater risk heightens the need for trust in one's physician [9].

The present study has some clear limitations such as the inclusion of a convenience sample of predominantly female students. Future research should further support and extend the present results, for example by studying the effects of pre-consultation information on actual treatment outcomes in patient samples.

\subsection{Conclusion}

In sum, these findings suggest that written pre-consultation information about a physician's competence and empathic skills can influence trust in one's physician, independent of the severity of a medical condition, as well as expected treatment outcomes.

\subsection{Practice Implications}

The present results indicate that online information about the competence and empathic skills of physicians can impact people's trust and expectations, which are important predictors of treatment outcomes. Consequently, physicians and hospital staff may want to take control of the information available on the internet by, for example, providing profiles on hospital websites highlighting competence and empathy of healthcare providers.

\section{Acknowledgments}

We thank Elise Bets for her active involvement in study setup and data collection.

\section{Conflicts of interest}

None

\section{Funding}

The work of KP and AE is supported by the Netherlands Organization for Scientific Research (NWO Vici grant number 45316004). The work of LV is supported by the Dutch Cancer Society (KWF Young Investigator Grant 10392) and the Netherlands Institute for Advanced Study in the Humanities and Social Sciences (NIAS-KNAW).

\section{Author contributions}

Kaya Peerdeman: Conceptualization, Methodology, Investigation, Formal analysis, Visualization, Data Curation, Project administration, Writing- Original draft preparation, Writing- Reviewing and Editing. 
Chris Hinnen: Conceptualization, Methodology, Writing- Original draft preparation, Writing- Reviewing and Editing.

Liesbeth van Vliet: Conceptualization, Methodology, Writing- Reviewing and Editing.

Andrea Evers: Conceptualization, Methodology, Writing- Reviewing and Editing.

\section{References}

[1] D.A. Hanauer, K. Zheng, D.C. Singer, A. Gebremariam, M.M. Davis, Public awareness, perception, and use of online physician rating sites, J Amer Med Assoc 311 (2014) 734-5, doi: 10.1001/jama.2013.283194.

[2] T. Lagu, J. Haskell, E. Cooper, D.A. Harris, A. Murray, R.L. Gardner, Physician beliefs about online reporting of quality and experience data, J Gen Intern Med 34 (2019) 2542-8, doi: 10.1007/s11606019-05267-1.

[3] A. Lopez, A. Detz, N. Ratanawongsa, U. Sarkar, What patients say about their doctors online: A qualitative content analysis, J Gen Intern Med 27 (2012) 685-92, doi: 10.1007/s11606-011-1958-4.

[4] S. Li, A. Hubner, The impact of web-based ratings on patient choice of a primary care physician versus a specialist: Randomized controlled experiment, J Med Internet Res 21 (2019) e11188, doi: $10.2196 / 11188$.

[5] M.A. Hillen, H.C. de Haes, L.J. Stalpers, J.H. Klinkenbijl, E.H. Eddes, P.N. Butow, J. van der Vloodt, H.W. van Laarhoven, E.M. Smets, How can communication by oncologists enhance patients' trust? An experimental study, Ann Oncol 25 (2014) 896-901, doi: 10.1093/annonc/mdu027.

[6] C.E. Ashton-James, T. Forouzanfar, D. Costa, The contribution of patients' presurgery perceptions of surgeon attributes to the experience of trust and pain during third molar surgery, Pain Rep 4 (2019) e754, doi: 10.1097/pr9.0000000000000754.

[7] C. Hinnen, G. Pool, N. Holwerda, M. Sprangers, R. Sanderman, M. Hagedoorn, Lower levels of trust in one's physician is associated with more distress over time in more anxiously attached individuals with cancer, Gen Hosp Psychiatry 36 (2014) 382-7, doi: 10.1016/j.genhosppsych.2014.03.005.

[8] N. Holwerda, R. Sanderman, G. Pool, C. Hinnen, J.A. Langendijk, W.A. Bemelman, M. Hagedoorn, M.A. Sprangers, Do patients trust their physician? The role of attachment style in the patient-physician relationship within one year after a cancer diagnosis, Acta Oncol 52 (2013) 110-7, doi: 10.3109/0284186x.2012.689856.

[9] M.A. Hall, E. Dugan, B.Y. Zheng, A.K. Mishra, Trust in physicians and medical institutions: What is it, can it be measured, and does it matter?, Milbank Quarterly 79 (2001) 613-39, doi: Doi 10.1111/1468-0009.00223.

[10] C. Lin, R. Clark, P. Tu, H.B. Bosworth, L.L. Zullig, Breast cancer oral anti-cancer medication adherence: A systematic review of psychosocial motivators and barriers, Breast Cancer Res Treat 165 (2017) 247-60, doi: 10.1007/s10549-017-4317-2.

[11] N. Ernstmann, M. Wirtz, A. Nitzsche, S.E. Gross, L. Ansmann, T.D. Gloede, J. Jung, H. Pfaff, W. Baumann, S. Schmitz, M. Neumann, Patients' trust in physician, patient enablement, and healthrelated quality of life during colon cancer treatment, J Cancer Educ 32 (2017) 571-9, doi: 10.1007/s13187-017-1166-y.

[12] L.C. Howe, J.P. Goyer, A.J. Crum, Harnessing the placebo effect: Exploring the influence of physician characteristics on placebo response, Health Psychol 36 (2017) 1074-82, doi: 10.1037/hea0000499.

[13] F. Jones, P. Harris, H. Waller, A. Coggins, Adherence to an exercise prescription scheme: The role of expectations, self-efficacy, stage of change and psychological well-being, British Journal of Health Psychology 10 (2005) 359-78, doi: 10.1348/135910704x24798.

[14] T.M. Haanstra, S.J. Kamper, C.M. Williams, A.S. Spriensma, C.W. Lin, C.G. Maher, H.C. de Vet, R.W. Ostelo, Does adherence to treatment mediate the relationship between patients' treatment 
outcome expectancies and the outcomes of pain intensity and recovery from acute low back pain?, PAIN 156 (2015) 1530-6, doi: 10.1097/j.pain.0000000000000198.

[15] K.J. Peerdeman, A.I.M. van Laarhoven, S.M. Keij, L. Vase, M.M. Rovers, M.L. Peters, A.W.M. Evers, Relieving patients' pain with expectation interventions: A meta-analysis, PAIN 157 (2016) 1179-91, doi: 10.1097/j.pain.0000000000000540.

[16] G.L. Petersen, N.B. Finnerup, L. Colloca, M. Amanzio, D.D. Price, T.S. Jensen, L. Vase, The magnitude of nocebo effects in pain: A meta-analysis, PAIN 155 (2014) 1426-34, doi: 10.1016/j.pain.2014.04.016.

[17] L.M. van Vliet, M.A. Hillen, E. van der Wall, N. Plum, J.M. Bensing, How to create and administer scripted video-vignettes in an experimental study on disclosure of a palliative breast cancer diagnosis, Patient Educ Couns 91 (2013) 56-64, doi: 10.1016/j.pec.2012.10.017.

[18] J.M. Bensing, W. Verheul, The silent healer: The role of communication in placebo effects, Patient Educ Couns 80 (2010) 293-9, doi: 10.1016/j.pec.2010.05.033.

[19] L.M. van Vliet, E. van der Wall, A. Albada, P.M. Spreeuwenberg, W. Verheul, J.M. Bensing, The validity of using analogue patients in practitioner-patient communication research: systematic review and meta-analysis, J Gen Intern Med 27 (2012) 1528-43, doi: 10.1007/s11606-012-2111-8.

[20] S.M. Bachinger, A.M. Kolk, E.M. Smets, Patients' trust in their physician-psychometric properties of the Dutch version of the "Wake Forest Physician Trust Scale", Patient Educ Couns 76 (2009) 126-31, doi: 10.1016/j.pec.2008.11.020.

[21] C. Lo, A. Walsh, M. Mikulincer, L. Gagliese, C. Zimmermann, G. Rodin, Measuring attachment security in patients with advanced cancer: psychometric properties of a modified and brief Experiences in Close Relationships scale, Psychooncology 18 (2009) 490-9, doi: 10.1002/pon.1417.

[22] T. Yamagishi, M. Yamagishi, Trust and commitment in the United States and Japan, Motivation and Emotion 18 (1994) 129-66, doi: 10.1007/bf02249397.

[23] A.F. Hayes, Introduction to mediation, moderation, and conditional process analysis: A regressionbased approach, 2nd ed., Guilford Publications, New York, 2017.

[24] A.W.M. Evers, L. Colloca, C. Blease, M. Annoni, L.Y. Atlas, F. Benedetti, U. Bingel, C. Buchel, C. Carvalho, B. Colagiuri, A.J. Crum, P. Enck, J. Gaab, A.L. Geers, J. Howick, K.B. Jensen, I. Kirsch, K. Meissner, V. Napadow, K.J. Peerdeman, A. Raz, W. Rief, L. Vase, T.D. Wager, B.E. Wampold, K. Weimer, K. Wiech, T.J. Kaptchuk, R. Klinger, J.M. Kelley, Implications of Placebo and Nocebo Effects for Clinical Practice: Expert Consensus, Psychother Psychosom 87 (2018) 204-10, doi: 10.1159/000490354. 


\section{Appendix: English translation of vignette}

Differences between the high and low variants of the vignette are underlined.

\section{INFORMATION ABOUT SITUATION AND SURGERY}

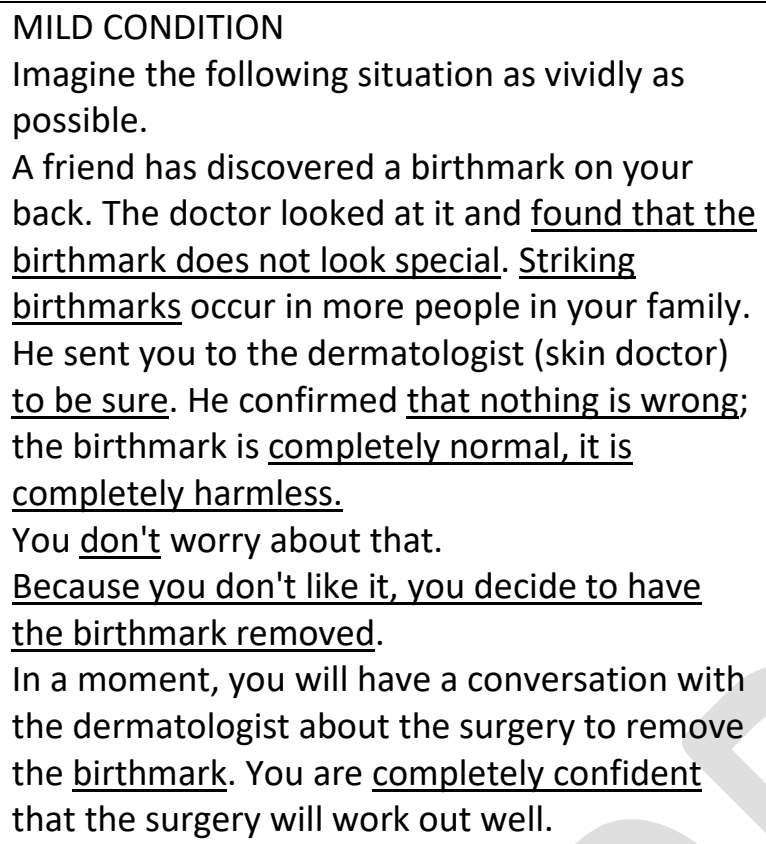

The surgery that you will undergo is a minor procedure that will be performed under local anesthesia.

It is not medically necessary that the surgery be performed, but you only do this for cosmetic reasons.

There are no serious risks associated with the surgery.

The birthmark can be easily removed at once due to the size and location of the tumor. After the surgery you will no longer have to check up with the dermatologist.

\section{SEVERE CONDITION}

Imagine the following situation as vividly as possible.

A friend has discovered a birthmark on your back. The doctor looked at it and did not trust the birthmark at all. Skin cancer occurs in more people in your family.

He immediately sent you to the dermatologist (skin doctor). He confirmed the worst nightmare; the birthmark is a melanoma, an aggressive form of skin cancer. You worry about that a lot. Due to the risk of metastases, the melanoma must be removed as quickly as possible. In a moment, you will have a conversation with the dermatologist about the surgery to remove the melanoma. You are terribly afraid that the surgery will not work out well.

\section{SEVERE SURGERY}

The surgery that you will undergo is an important procedure that will be performed under local anesthesia.

It is medically necessary that the surgery be performed as quickly as possible because of the risk of metastases.

There are serious risks associated with the surgery.

The cancer may not be removed at once due to the size and location of the tumor.

After the surgery you will still have to check up regularly with the dermatologist. 
INFORMATION ABOUT THE PHYSICIAN

\begin{tabular}{|c|c|}
\hline LOW COMPETENCE & HIGH COMPETENCE \\
\hline $\begin{array}{l}\text { You decide to gather some information about } \\
\text { the dermatologist who will perform the surgery. } \\
\text { On the website of the hospital you read that } \\
\text { this doctor graduated last year and just started } \\
\text { working in this hospital. } \\
\text { He is not yet in training as a medical specialist. } \\
\text { You cannot find any information about whether } \\
\text { he specializes in this surgery and whether he } \\
\text { performs it often. } \\
\text { He is mainly concerned with eczema. } \\
\text { Coincidentally, you also hear from a friend who } \\
\text { has been with him before, that the surgery had } \\
\text { not gone well with her. }\end{array}$ & $\begin{array}{l}\text { You decide to gather some information about } \\
\text { the dermatologist who will perform the surgery. } \\
\text { On the website of the hospital you read that } \\
\text { this doctor is very experienced and has been } \\
\text { working in this hospital for } 26 \text { years. } \\
\text { He frequently trains young doctors to become } \\
\text { medical specialists. } \\
\text { You read that he specializes in this surgery and } \\
\text { that he performs it very often. } \\
\text { He is an international expert in melanoma. } \\
\text { Coincidentally, you also hear from a friend who } \\
\text { has been with him before, that the surgery } \\
\text { went very well with her. }\end{array}$ \\
\hline $\begin{array}{l}\text { LOW EMPATHY } \\
\text { Then you also google for the experiences of } \\
\text { patients with this doctor. The doctor appears } \\
\text { not to be very popular with patients. He is } \\
\text { described as cold and distant. } \\
\text { He has little interest in the patient as a person. } \\
\text { He does not take the patient's concerns } \\
\text { seriously. } \\
\text { Coincidentally, you also read that this doctor } \\
\text { received a score of } 4 \text { on a } 1-10 \text { scale in a recent } \\
\text { survey of the most sensitive and empathetic } \\
\text { doctors. }\end{array}$ & $\begin{array}{l}\text { HIGH EMPATHY } \\
\text { Then you also google for the experiences of } \\
\text { patients with this doctor. The doctor appears to } \\
\text { be very popular with patients. He is described } \\
\text { as warm and friendly. } \\
\text { He is very interested in the patient as a person. } \\
\text { He takes the patient's concerns seriously. } \\
\text { Coincidentally, you also read that this doctor } \\
\text { received a score of } 9 \text { on a } 1-10 \text { scale in a recent } \\
\text { survey of the most sensitive and empathetic } \\
\text { doctors. }\end{array}$ \\
\hline
\end{tabular}

